\title{
Silencio obligado*
}

\author{
Eva Escribano
}

http:// dx.doi.org/ 10.12795/mAG Azin.2015.i23.06

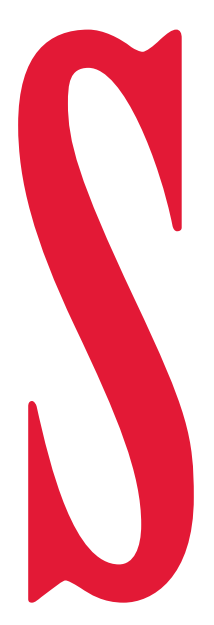

e han saludado entre ellos a las puertas del bar con esa manera algo mecánica que tienen de saludarse. Como sabiendo $\mathrm{y}$ no lo que tienen que hacer, lo que se espera de ellos en cada momento, con palmaditas en los hombros, como midiendo la efusividad. "No nos vemos desde hace meses", explica Christian, el Buen Alemán, mientras entramos, y a mí la explicación me vale y pienso que entonces saludarme a mí ha sido algo fácil para esta gente porque solo han tenido que extender la mano y, si acaso, medir la fuerza con la que me apretaban

los nudillos. Simplificar los movimientos les sienta bien. Con Christian han tenido que elegir el ángulo de los brazos, el tiempo de palmeteo en el omoplato, la distancia entre caderas y la sonrisa de después. Conmigo ha sido simple y directo. Creo que hasta les he hecho un favor.

Son gente de provincias, amigos de Christian que surgieron en racimos en las soledades de la campiña bávara, ahora estudiantes de una ciudad provincial, Ratisbona.

Con éstos no puede haber problema, pienso, porque parecen gente campechana y franca. Probablemente ni siquiera hayan entablado relación con una española de esta manera en meses, o incluso años, así que les resultaré curiosa, hasta cierto punto atractiva. Naturalmente caeremos en las conversaciones sobre estereotipos nacionales que tanto salvan el pellejo durante los silencios en la mesa; pero no hay problema porque para eso estoy en Alemania, me recuerdo, para empaparme de su cultura y que ellos se empapen de la mía. En parte, claro.

La realidad es que he venido a Alemania porque no me quedó otra. No porque fuera mi deseo intrínseco el compartir espacio vital con alemanes o el aprender las Wunderwerke del idioma. De hecho, el único alemán que me interesa en el mundo es Christian. Y la única española que le interesa en el mundo a Christian soy yo. Las otras circunstancias entran dentro de lo colateral. Eso es un hecho comprobado. Porque, en fin, no se explica de otra manera que alguien tan vaga como yo haya acabado con alguien tan diligente. O que alguien tan soso como él esté compartiendo plato con semejante bomba de extroversión. No, no se explica. Probablemente la abuela de Christian estuviera pensando en esos términoscuando, levantándose de la mecedora matriarcal, preguntócon el dedo en alto: “ ¿española? ¿Por qué española, a ver? ¿Por qué no alemana?”. Con toda seguridad ella sabe que no vine a Alemania porque me interesara la cultura alemana sino porque me interesaba un único hombre alemán, su nieto.

Para ella yo debía ser el culmen de la globalización y entraba en casa para sembrar guerra. Luego se puso a regalarme calcetines y todos en paz.

Al sentarnos a la mesa, pierdo la voz durante un instante aunque con naturalidad. Christian, mi portavoz oficial para estos momentos de afonía, informa a la camarera de que una Helles me vendrá bien. Los colegas comienzan a charlar mientras tanto con el marcado acento bávaro de las tierras Oberpfalz.

"Los bávaros son los andaluces de Alemania", me dijo la semana pasada un tinerfeño. "No hay quien les entienda cuando hablan, pero en el fondo son tan simpaticones que se les perdona”. Él también se vino al país porque no le quedó otra y también le perdonamos cosas. Desde que coincidimos en la academia nos dedicamos a profundizar en la creación de un idioma germañol propio que acepta variantes como el "ich proponiere dich", "lipiere mit dir" y el "sich wie Suppe bleiben" y que trae por la calle de la amargura a nuestra profesora Steffy, también de provincias.

"Sois de lo que no hay", nos dice mientras borra la pizarra, al término de las clases. A mí me gustaría decirle que somos

* Capítulo de la obra żTe has venido a Alemania Pepe? Relatos de nuevos inmigrantes españoles en Alemania coordinada por Ralf Junkerjürgen, Julia Sánchez Rodríguez, Trinidad Bonachera Álvarez y Hubert Pöppel 
así porque no nos enteramos de la misa la mitad, aunque no sea su culpa, y porque todavía estamos esencialmente acojonados de haber entrado en Alemania y no ver el momento de salir de ella. Nos hallamos en pleno caldo de cultivo del llamado choque cultural (aunque tenga algo más de rozadura, para ser exactos). Pero siempre me callo.

Los españoles gozamos de un statu quo especial dentro de la academia y trabajamos por mantenerlo: estamos llegando en bandadas, como albatros migratorios, haciéndonos los graciosillos en las aulas, mutilando el idioma con nuestros "furr dish", nuestros "aus Espanien" y la repetición absurda del "aber natürlich!"”, que parece ser lo único que decimos bien del vocabulario. Por supuesto, debemos ser en términos porcentuales la casta nacional que más dinero ingresa en la academia. Quizás sea esa la única razón por la que Steffy todavía nos sigue sonriendo al tinerfeño y a mí, porque le ayudamos muchísimo con la Miete de Múnich.

\section{La Erdinger espumosa}

concentra mi atención durante los siguientes minutos y los provincianos siguen hablando en este bar de Ratisbona. De vez en cuando Christian me dirige la mirada de "ite estás enterando de algo?”, para asegurarse, y yo respondo con un parpadeo de ojos más largo de lo normal.

"No pasa nada", le comunico por telepatía, "habláis de pena, como en ladridos blandos, pero
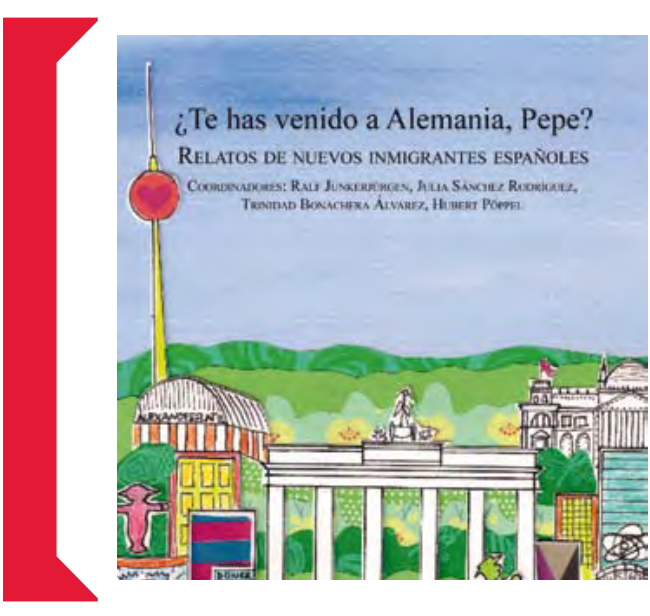

Desde el principio". Porque los minutos pasan, la Erdinger se va vaciando en mi boca. La música del bar comienza a parecerse a los hilos musicales de la Bayern.3, con los eternos hits de los noventa por los que no pasan los años. Y por allí no aparece el inglés.

Carraspeo, me remuevo inquieta en el asiento. ¿Cómo puede ser posible que todavía yo no haya pronunciado palabra? Intento atender a lo que se dice y formar frases en la cabeza: "Ich denke, dass...", pero por algún motivo no puedo continuarlas o llegan demasiado tarde. Al poco ya estoy lanzando miradas acusadoras a Christian quien, para entonces, está muy lejos de mí, aunque esté sentado a menos de un metro de distancia. Miro un reloj de pared y compruebo que llevo sin decir nada exactamente treinta y cinco minutos. La situación no parece que vaya a cambiar. Así que es factible afirmar que me estoy quedando muda. La última vez que perdí la voz, aunque de forma menos total, a nadie de mi entorno le importó lo más mínimo. Ocurrió nada más poner mis pies en Múnich. En aquella ocasión, Christian no acudió en mi ayuda porque estaba en Ingolstadt y el único testigo del suceso seguramente no se acuerde ya de mí.

Yo lo recuerdo bávaro, pero los años en la capital habían limado su acento. Se sentaba tras la mesa de secretaría de la Academia de Bellas Artes, controlando las admisiones e incidencias. Nada más poner un pie allí, acalorada, supe que natural". Ya me viene pasando a veces que los alemanes necesitan romper una especie de película invisible que los separa de mí tras el primer contacto. Esto lleva su tiempo. Es como si tardaran en darse cuenta de que la mujer que acaba de llegar al grupo lo ha hecho para quedarse, durante las siguientes horas, sin solución y aunque no hable el idioma. Se produce entonces un momento de epifanía y entre curiosidad y verdadera devoción por el protocolo, se giran hacia mí, cambian al inglés y comenzamos a hablar. Conocer y aceptar este modus operandi es llegar hasta el cogollo de los misterios de la sociabilidad alemana. Hay muchos compatriotas que no lo entienden o que no saben esperar. Suelen ser los que a veces se olvidan de que un alemán tiene derecho a hablar alemán, por residir esencialmente en Alemania.

Hoy, sin embargo, los compatriotas podrían señalarme con el dedo, sacarme la lengua y decirme "ya te lo avisamos. aquel hombre había entablado conversación con muchos estudiantes de Erasmus y, a la vez, probablemente con ninguno.

Tenía ese aire arcaico de roedor bibliotecario, de quien no pisa la calle a menos que sea estrictamente necesario. Tras saludarle en alemán, adopté mi mueca de disculpas, y pregunté: "Do you speak English? I just came to order a library card and..."

Otra nota para el decálogo del español en Alemania: si un alemán te interrumpe sin haber terminado tu frase, sabes que por fuerza se cuece algo gordo entre ambos. Aquel hombre enjuto me interrumpió, detrás de las gafas: "Sie sind in Deutschland".

Comenzaba la prueba de fuego, el choque lingüístico.

"Ja, klar... Ich weiß, aber..."

"Dann sollten Sie deutsch sprechen, oder? Meinen Sie nicht?" 
Su lógica era aplastante, desde luego. Es la clase de lógica que nos produce urticaria emocional precisamente por lo monolítica que es. No podemos luchar contra ella. Hacen falta, quizás, otros métodos. ¿Cuáles tenía yo, en aquel momento? Inspirar compasión, suponía, no demasiado digno para mí aunque eso mejor que nada, eso mejor que salir de la biblioteca sin tarjeta. Pero, ¿cómo enlazar mi vocabulario de recién llegada para pedir clemencia en la lengua de Goethe? Me molestaba sonar como una inmigrante más, me hartaba que me catalogaran como española inepta. Por aquel entonces, yo pensaba que gozaba de un status especial, un estatus basado exclusivamente en la figura del Buen Alemán, Christian. Pero una debe reconocer sus limitaciones cuando son evidentes.

"Sorry, I just came from abroad and..., empecé otra vez.

"Versuchen Sie es".

"Wie... bitte?".

"Versuchen Sie, mit mir auf Deutsch zu reden".

"Bitte? Nochmal... Wiederholen? Ja?".

La estrategia de hacerse la sueca había funcionado a otros compatriotas. En la mayoría de los casos, los administrativos ponían los ojos en blanco y cambiaban al inglés, para ahorrarse tiempo y paciencia. Tampoco era digno. Pero funcionaba.

"Auf... Deutsch... zu reden! Mit mir! Verstehen Sie?", este hombre era todo aguante y todo recochineo, a la vez.

"Ich... kann das, es, nein, das nicht...

"Warum?"

"Weil ich bin neu in die, der... die Estadt. Meine Deutsch ist... nicht gut".

"Doch, doch! Versuchen Sie es!"

Dentro de mi cabeza todo estaba muy claro: "Usted tiene más razón que un santo, pero por favor, no me toree y sea bueno conmigo. El karma se lo agradecerá. Llevo en Múnich una semana y la ciudad late demasiado deprisa. Tengo que adaptarme a marchas forzadas a ella y no me lo esperaba. Pensaba que todo iba a ser coser y cantar. Mire, necesito una tarjeta de visitante para consultar los fondos de la biblioteca porque tengo unas prácticas en un museo aburridísimo que da pena visitarlo. Esto tampoco me lo esperaba. De hecho, me drena la energía. ¿No lo entiende? Cuanto antes me ayude, antes desapareceré por la puerta".

Pero al final, mi discurso sonó parecido a esto:

"Ich brauche eine Karte, eine Estudenten Karte... Aber ich bin nicht eine Estudentin, ja? Weil ich arbeite in, im, Bayerisches Nationalmuseum... Und ich brauche eine Karte. BesuchenKarte denn. Für die Bücher, für lesen. Ja. Bitte.”.

Entre el secretario y yo cayó una pelota de silencio que acabó a sus pies. Aquel hombre le dio una patada mientras sonreía y alargaba la mano hacia uno de los formularios. "Sehen Sie? Es war nicht so schwer, oder? Sie können perfekt Deutsch!"

Sonreí por hacer algo mundano. En realidad, tenía ganas de alumbrarlo con una pequeña muestra de temperamento. Su petición había sido lógica, por encima de cualquier compasión. Así que, en silencio, obtuve la tarjeta y me marché de allí.

Sentada en el bar y quedándome muda, me acuerdo de aquel bibliotecario que no admitía afonías o cambios en el idioma. Aquella sería una buena anécdota que compartir con estos bávaros ahora mismo. "No os iréis a creer lo que me pasó durante mi primera semana en Múnich... Aquello fue humillante de verdad", y otros tantos órdagos a la comunicación, podría irlos enumerando, incluso con los panaderos turcos y griegos. Pero tampoco sé cómo empezar esa frase o cómo interrumpir. Yo, que solía dirigir las conversaciones hacia un derrotero u otro en mi tierra natal. Si me vieran ahora los que se quejaban de que yo hablaba demasiado, no cabrían en sí de gozo.

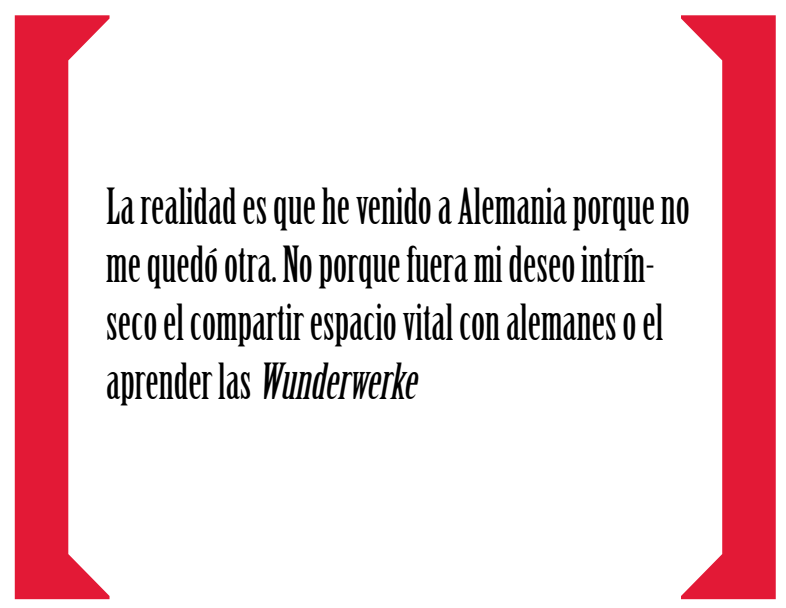

La tranquilidad con la que me ignoran los bávaros comienza a embargarme a mí, poco a poco. No es claudicar, es aceptar la situación, me recuerdo. Otra de las ventajas de ser inmigrante, que todo es injusto y muy justo a la vez. Podemos aceptar tranquilamente que hemos dejado de ser quien somos, aunque sea en una parte mínima, al atravesar la frontera. Los alemanes no tienen por qué saberlo.

$Y$ es esta tranquilidad que reina la que me lleva a recostarme al final en la silla, disfrutar de los últimos tragos de la Erdinger en silencio y concentrarme en mi proceso de desaparición. Porque ahora estoy desapareciendo y volviéndome invisible. De hecho, es como si mi piel hubiera perdido la consistencia de mis veintidós años y se volviera translúcida. En este momento exacto sé que no existe una razón que me impida esfumarme de este bar, dejando tras de mí un epitafio etéreo que diga: "Aquí se esfumó una inmigrante española más. Se sintió en Alemania como en casa, pero a veces, fuera de ella. 
Esta dualidad la mantuvo con vida. Sobrevivió como pudo, se sacó las castañas, intentó aprender el idioma de Goethe, hizo concesiones y cambió de personalidad. Se desvaneció en Ratisbona una noche cualquiera, tras una hora y quince minutos sin pronunciar palabra".

No siempre fue así. Aunque yo haya tenido la ligera sensación de que un alemán se tiene que regular las gafas para conocerme realmente, desde el principio también tuve la sensación de que a mí se me veía más de lo normal. Que yo destacaba contra el plomizo cielo de marzo y los horizontes de las calles. Pero, sobre todo, al lado de los semáforos. Es allí entonces donde el inmigrante español se deja ver en todo su esplendor y adquiere un protagonismo absoluto durante segundos.

Por ejemplo, eran las doce del mediodía de un día entre semana en la ciudad de Ingolstadt. El Buen Alemán estaba en clase y parecía que la ciudad entera estuviera también en clase porque el centro permanecía desierto. Excepto en las inmediaciones del parque de Klenze, donde una turba esperaba a ambos lados de la Avenida Schloßlände a que el semáforo se pusiera en verde. Recuerdo que pensé: "en la vida he visto un semáforo tan lento”. Los números digitales cambiaban con la velocidad de una oruga arrastrándose. Y también pensé en los segundos de mi existencia vital que se iban descontando mientras yo y los otros esperábamos.

Me cercioré de que no hubiera niños en las inmediaciones. Porque una cosa es aprovechar los segundos de vida que se tienen y otra muy diferente, dar mal ejemplo. Y crucé como se cruzan las avenidas desiertas en España, con ese paso afable y carente de toda maldad. Resulta que tres años más tarde comprobé que, en las calles de Tokio, los japoneses también esperaban a que el semáforo diera su consentimiento verde para cruzar. Sin embargo, me seguían de buena gana y rompíamos el protocolo nipón en grupo, como si pensaran: "bueno, ya, total... Por uno más que lo rompa... El orden establecido va a continuar su curso de cualquier manera”. Pero en Ingolstadt no. La mímica estuvo fuera de lugar .

A mí solo me siguieron las miradas de aquellas personas ancladas en su sitio, estáticas. Pensé, miradme, soy una pionera, con algo de vergüenza también, porque en aquella avenida no había nada para ver, excepto mi indiferencia hacia las normas. Así que yo era tremendamente visible para todos en aquel momento. Un recordatorio visual de los descaros del inmigrante. Porque me parecía escuchar sus pensamientos a ambos lados del asfalto: "esa no es de aquí, seguro", o "mírala, por la desfachatez, debe ser mediterránea”, o incluso “¿por qué no habré nacido yo en un país con semáforos más rápidos?” Es muy fácil escuchar los pensamientos de la comunidad alemana cuando se cruza en rojo una de las avenidas centrales de Ingolstadt.

Todavía recuerdo el sonido de mis pasos al avanzar. La sensación de que aquello no acababa nunca. Y el alivio que sentí cuando inalmente tomé el puente hacia el parque, perdiéndolos de vista.

Sentada e invisible a la mesa, pienso ahora que debería haber firmado un contrato mental conmigo misma al coger el avión. Mi humillación y soledad dolerían bastante menos, me parece. Debería haberlo firmado en contra de la idealización, que es la faceta que siempre me mata a posteriori, vaya a donde vaya, cuando la realidad no surge como la esperaba. Luego podría haber ido añadiendo diferentes cláusulas al contrato, de acuerdo a mis circunstancias personales. Así, pienso, aunque siguiera siendo invisible para los bávaros, sería consecuente conmigo misma. Podría crear una deinición intransferible del inmigrante en los tiempos que corren.

En la práctica, sin embargo, sé que esto nunca me funcionará. Y es que la idealización es parte intrínseca de mi realidad como inmigrante en Alemania. Si me pongo a limar esta palabra, entonces nunca estaré en paz conmigo misma. Entonces desapareceré sin solución incluso delante de mis ojos.

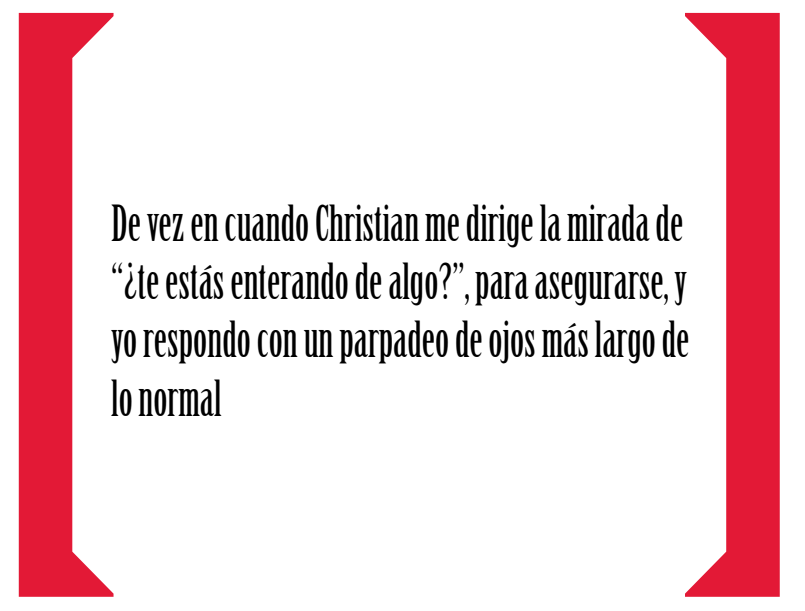

Por idealización no me refiero al embellecimiento irracional del país o de la idiosincrasia de su cultura, sino a la abstracción continua que supone, para el inmigrante, tener un ideal. Sea del tipo que sea. El ideal de mejorar, el ideal de volver, el ideal de ganar más dinero, el de aprender el idioma, el de huir, el de no acabar relaciones, el de empezarlas, el de aceptar la distancia, el de ser más feliz, el de sufrir un poco menos, el de no perder las raíces, el de levantarse en otras latitudes, el de demostrar que puede hacerse... En definitiva, el ideal de seguir avanzando a un ritmo que solo 
podemos definir nosotros.

Esa dimensión nos pertenece. Somos los únicos responsables de ella. En otro tiempo, en otras circunstancias, nuestra vida pudiera haber sido totalmente diferente. Pero hemos acabado en Alemania y es en este hecho donde tenemos que proyectar toda la fuerza de nuestros ideales. Incluso si estos cambian cada día y no son tan estáticos como los peatones alemanes. De hecho, probablemente no lo sean. No nos queda otra porque eso es lo que nos define.

A veces olvido todo esto y a veces vuelve a mí con fuerza demoledora. Todavía queda esperanza, me digo con una sonrisa. Miro mi vaso vacío y recuerdo aquella vez en que pensé que el término Radler designaba una marca de cerveza de la zona, junto a las Augustiner, las Erdinger y Paulaner. Radler, claro. La confusión me dejó bebiendo aquella vez una cerveza con demasiado limón que me sabía a rayos. Nunca volveré a cometer ese error.

"Ich hätte gerne ein Helles, bitte", le pido a la camarera cuando la veo aproximarse. Mi voz suena extraña, después de tanto tiempo sin usarse. Mis manos ya no son transparentes, constato al instante, sino morenas.

Christian se gira entonces. Su mirada parece no reconocerme. "Ah, ipero si estás aquí! ¿Dónde te habías metido?", pregunta.
1 Algo así como: "yo te propongo"; "flipar contigo"; "quedarse sopa; dormirse".

2 "Furr dish", en vez de "für dich" - "para ti"; "aus Espanien” - "de España"; "aber natürlich" (alemán correcto) - "por supuesto".

3 "Creo que...", "supongo que...".

4 “Usted está en Alemania”; “Claro que sí... Yo sé, pero..."; “Entonces debería de hablar alemán. ¿No cree usted?"

5 “Inténtelo"; “¿Cómo? ¿Por favor?”; “Intente hablar conmigo en alemán"; “¿Cómo? ¿Otra vez... repetir? ¿Sí?"
6 "Hablar... conmigo... en alemán. ¿Entiende?"; "Yo... lo puedo, esto, no, esto no..."; ¿ ¿Por qué?; "Porque yo nuevo estoy en la, el... la ciutat. Mía alemán es... no bueno"; “iSí, sí, inténtelo!”

7 "Yo necesito una tarjeta, una tarjeta studantil... Pero yo una studianta no soy, ¿sí? Porque yo trabajo en el, en la Museo Nacional Bávaro... Y yo necesito una tarjeta. Tarjeta visitante pues. Para los libros, para leer. Sí. Por favor".

8 "Ve usted. Tampoco era tan difícil. Usted maneja perfectamente el alemán".

9 "Una cerveza rubia [aquí de trigo], por favor".

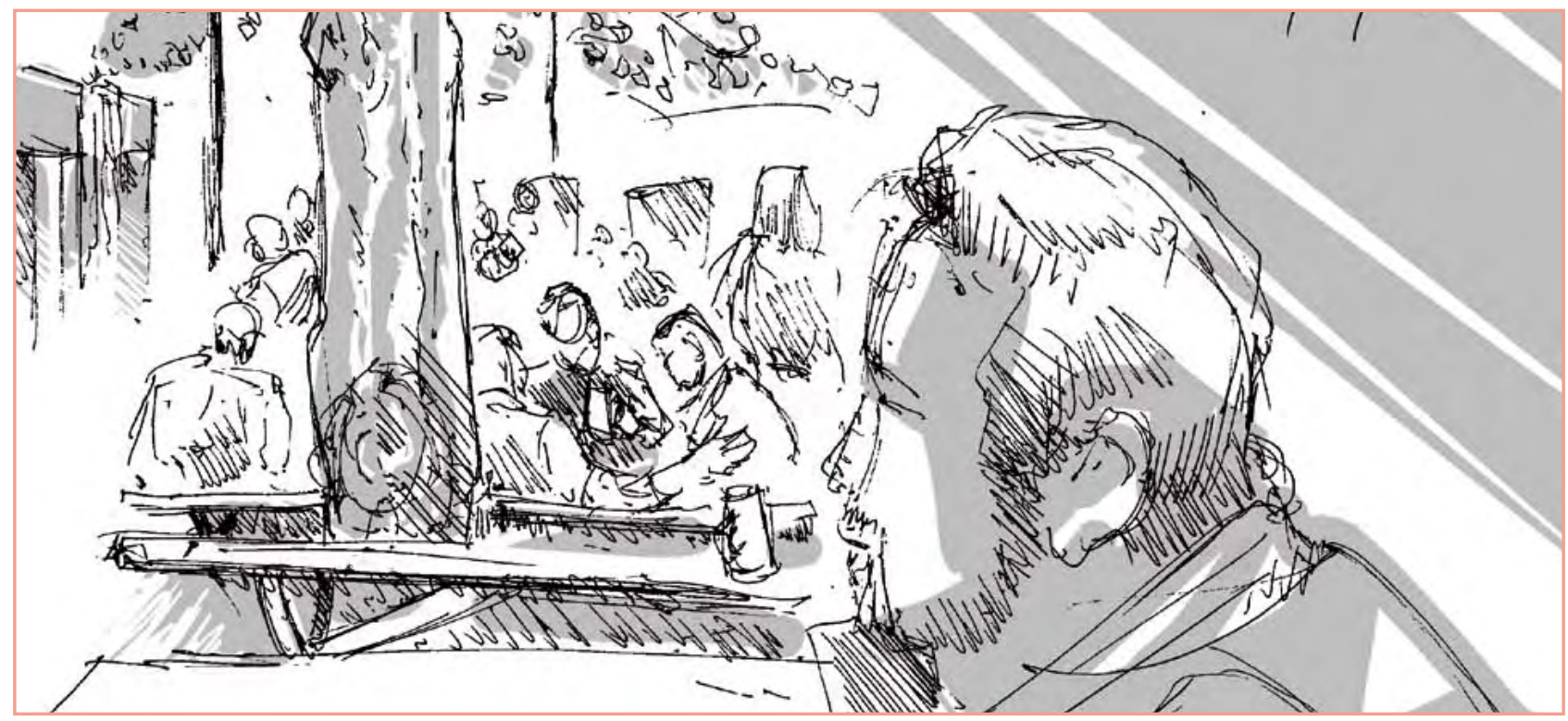

